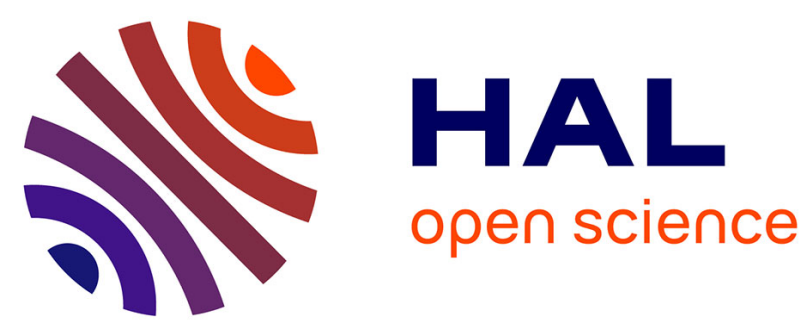

\title{
Experimental and modelling investigation of the thermal decomposition of $n$-dodecane
}

K.D. Dahm, P.S. Virk, R. Bounaceur, F. Battin-Leclerc, P.M. Marquaire, R. Fournet, E. Daniau, M. Bouchez

\section{- To cite this version:}

K.D. Dahm, P.S. Virk, R. Bounaceur, F. Battin-Leclerc, P.M. Marquaire, et al.. Experimental and modelling investigation of the thermal decomposition of n-dodecane. Journal of Analytical and Applied Pyrolysis, 2004, 71 (2), pp.865-881. 10.1016/j.jaap.2003.11.005 . hal-01168736

\section{HAL Id: hal-01168736 \\ https://hal.science/hal-01168736}

Submitted on 20 Feb 2020

HAL is a multi-disciplinary open access archive for the deposit and dissemination of scientific research documents, whether they are published or not. The documents may come from teaching and research institutions in France or abroad, or from public or private research centers.
L'archive ouverte pluridisciplinaire HAL, est destinée au dépôt et à la diffusion de documents scientifiques de niveau recherche, publiés ou non, émanant des établissements d'enseignement et de recherche français ou étrangers, des laboratoires publics ou privés. 


\title{
Experimental and modelling investigation of the thermal decomposition of $n$-dodecane
}

\author{
K.D. Dahm ${ }^{\text {a }}$, P.S. Virk ${ }^{\text {b }}$, R. Bounaceur ${ }^{\mathrm{c}, *}$, F. Battin-Leclerc ${ }^{\mathrm{d}}$,

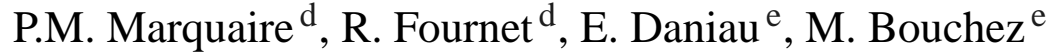 \\ a Department of Chemical Engineering, College of Engineering, Rowan University, \\ 201 Mullica Hill Road, Glassboro, NJ 08028-1701, USA \\ ${ }^{\mathrm{b}}$ Department of Chemical Engineering, Massachusetts Institute of Technology, Cambridge, MA 02139, USA \\ ${ }^{\mathrm{c}}$ PROGEPI-ENSIC-CNRS, 1 rue Grandville, BP 451, 54001 Nancy, France \\ ${ }^{\mathrm{d}}$ DCPR-ENSIC-CNRS, 1 rue Grandville, BP 451, 54001 Nancy, France \\ ${ }^{\mathrm{e}}$ Flight Dynamics and Propulsion Department, MBDA France, 8 rue le Brix, 18020 Bourges, France
}

\begin{abstract}
An important challenge in developing the Scramjet engine is cooling of the walls. One possibility is circulating the fuel itself through the walls of the engine, with cooling achieved through the strongly endothermic decomposition of the fuel. This paper presents an experimental and modelling study of the pyrolysis of $n$-dodecane, a component of some jet fuels. The experiments have been performed in a stainless steel isothermal plug flow reactor at temperatures of 950,1000 and $1050 \mathrm{~K}$ and atmospheric pressure, with GC analysis of the end products, mainly methane, ethane and alkenes from $C_{2}$ to $C_{10}$. A detailed kinetic model containing 1175 reactions has been produced using EXGAS software. This model is able to represent with reasonable accuracy the experimental results presented here, both for the conversion of $n$-dodecane and for the formation of products, as well as literature data obtained from 623 to $823 \mathrm{~K}$.
\end{abstract}

Keywords: $n$-Dodecane; Thermal decomposition; Detailed kinetic mechanisms; Scramjet

\section{Introduction}

The Scramjet engine is the key enabling technology for sustained hypersonic flight, which could be used for high-speed missiles or could power hypersonic aircraft and spacecraft

\footnotetext{
* Corresponding author. Tel.: +33-383-175009; fax: +33-383-327308.

E-mail address: roda.bounaceur@ensic.inpl-nancy.fr (R. Bounaceur).
} 
into orbit. Scramjet is an acronym for Supersonic Combustion Ramjet. A ramjet has no moving parts and achieves compression of intake air by the forward speed of the vehicle. Air entering the intake of a supersonic aircraft is slowed by aerodynamic diffusion created by the inlet and diffuser. The expansion of hot gases accelerates the exhaust momentum to a velocity higher than that at the inlet and creates positive thrust. The Scramjet differs from the ramjet in that combustion takes place at supersonic air velocities through the engine and, theoretically, permits a flight speed from Mach 5 to Mach 10-12.

The development of Scramjet is complex and an important problem is linked with the cooling of the walls of the engine, in which the air enters at $1650 \mathrm{~K}$ at Mach 6 and at $4800 \mathrm{~K}$ at Mach 12 [1]. Research studies are on-going on the possibility to use the endothermic capabilities of the thermal decomposition of a fuel circulating on the composite or metallic material walls of the Scramjet in order to quantify the heat transfer in the cooled structures and the composition of the mixture entering the combustor [2,3]. The use of this technique requires accurate predictive models of the thermal decomposition of fuels, in order to quantify the heat transfer and the composition of the mixture entering the reaction chamber. Consequently, the objective of the present work is to study the thermal decomposition of a model fuel, $n$-dodecane, for temperatures from 400 to $1500 \mathrm{~K}$ and pressures from 0.5 to 50 bar. $n$-Dodecane is an important component of some jet fuels, such as NORPAR 12, JP 7 and JP 8 [3].

Only limited work has been published on the thermal decomposition of $n$-dodecane. Zhou et al. [4] have studied the vapor phase thermolysis of several straight-chain alkanes, including $n$-dodecane, in a stainless steel unpacked flow reactor at temperatures from 623 to $893 \mathrm{~K}$ and under atmospheric pressure. Yoon et al. [5,6] have reported some results on the thermal degradation of pure $n$-dodecane and $n$-dodecane mixtures containing different hydrogen donors, obtained in static stainless steel microreactors under temperatures from 773 to $823 \mathrm{~K}$ and pressures from 6.9 to 10 bar. Yu and Eser $[7,8]$ have studied the near critical and supercritical phase thermal decomposition of $\mathrm{C}_{10}-\mathrm{C}_{14}$ normal alkanes, including $n$-dodecane, in a Pyrex glass sealed tube under temperature from 673 to $723 \mathrm{~K}$ and pressures from 12.6 to 72.4 bar (the critical pressure of $n$-dodecane is 18.1 bar). In order to study the thermal decomposition of $n$-dodecane at higher temperatures than the previous papers $[4,8]$, the present paper presents measurements at 950, 1000 and $1050 \mathrm{~K}$.

\section{Experimental method and results}

\subsection{Experimental apparatus}

Fig. 1 shows the flowsheet for the experimental apparatus. Liquid dodecane feed rates of $0.04-0.35 \mathrm{ml} / \mathrm{min}$ were attainable using the VWR Mini-Pump with a variable head speed. Dodecane was pumped through flexible Tygon tubing attached to a Swagelok union T, where it entered the carrier gas line. The gas lines were $1 / 4$ in. $(6.35 \mathrm{~mm})$ o.d., $0.12 \mathrm{in}$. $(3.04 \mathrm{~mm})$ i.d. stainless steel tubing. The carrier gas was $99.9 \%$ pure nitrogen from BOC gas. Its flowrate was controlled by an Airco two-stage regulator and Nupro 1/4 in. (6.35 mm) needle valve, and measured by Gilmont size 3 flowmeters with glass float. The preheater, which consisted of two $8 \mathrm{ft}$ Fisher heating tapes coiled tightly around the steel tubing, was 


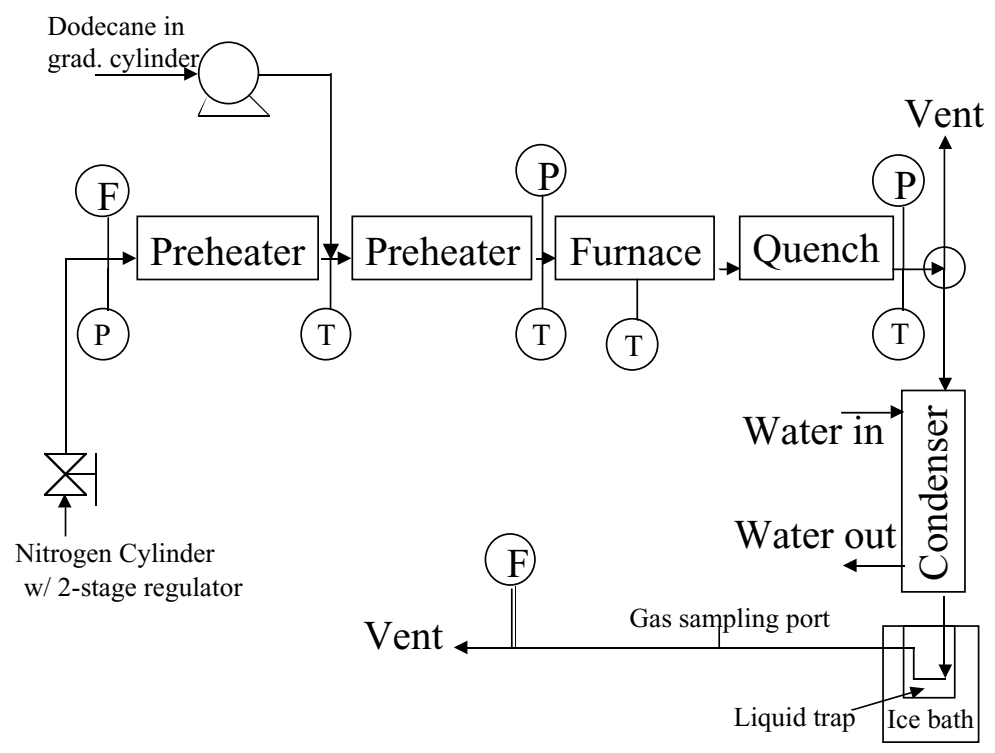

Fig. 1. Flowsheet for the experimental apparatus.

used to evaporate the dodecane. Omega $1 / 8 \mathrm{in} .(3.18 \mathrm{~mm})$ Iconel sheathed thermocouples and Marsh 0-30 psi (0-2 bar) pressure gauges were used to monitor the conditions of the gas entering and leaving the reactor and ensure that the reactor was operating at steady-state.

The reactor itself was a $2 \mathrm{ft}(61 \mathrm{~cm}), 0.25$ in. $(6.35 \mathrm{~mm})$ o.d., 0.12 in. $(3.04 \mathrm{~mm})$ i.d. stainless steel tube passing through a 3-zone Lab-Line furnace. The ends of the furnace were plugged with insulation to help insure that the interior temperature was uniform. Inside the furnace, three Chromega $0.032 \mathrm{in} .(0.8 \mathrm{~mm})$ base metal thermocouples were cemented to the walls of the reactor, spaced 4, 12 and 20 in. from the inlet. The reaction was considered isothermal if all three read the same temperature within $1{ }^{\circ} \mathrm{C}$ for the entire experiment. After leaving the reactor, the gas passed through an air-cooled heat exchanger that acted as a quench.

The collection/sampling system consisted of a water-cooled condenser with liquid trap, followed by a gas sampling port made with Supelco $9.5-\mathrm{mm}$ septum nuts screwed into Swagelok NPT fittings.

\subsection{Experimental procedure}

Carrier gas and dodecane flow rates were set such that the concentration of dodecane entering the reactor was $1.5 \times 10^{-4} \mathrm{~mol} / \mathrm{l}$. The gas leaving the reactor was vented until the reactor was operating at steady state at the desired temperature $(950,1000$ or $1050 \mathrm{~K})$, at which time the switching valve was used to divert it to the sampling apparatus. Each experiment lasted $30 \mathrm{~min}$.

Gas samples were taken 2 min after the run started, at the midpoint, and again $2 \mathrm{~min}$ before the end, and analysed using an HP 5890 gas chromatograph with HP-PLOT $\mathrm{Al}_{2} \mathrm{O}_{3}$ 
Table 1

Absolute and relative errors for basic experimental measurements

\begin{tabular}{lllll}
\hline Quantity & Instrument & Range of values & Abs. error & Error (\%) \\
\hline Carrier gas flowrate & Rotameter & $416-3313 \mathrm{ml} / \mathrm{min}$ & $22 \mathrm{ml} / \mathrm{min}$ & $0.7-5.3$ \\
Mass of substrate fed & Grad. cylind & $1.3-9.0 \mathrm{ml}$ & $0.04 \mathrm{ml}$ & $0.4-3$ \\
Gas product flowrate & Rotameter & $0.06-0.3 \mathrm{~g} / \mathrm{min}$ & $0.013 \mathrm{~g} / \mathrm{min}^{\mathrm{a}}$ & $4.3-22$ \\
Mass of liquid product & Balance & $0-3.7 \mathrm{~g}$ & $0.005 \mathrm{~g}$ & - \\
\hline
\end{tabular}

a The absolute error decreases over the bottom $\sim 10 \%$ of the rotameter's operating range, but is always at least $0.007 \mathrm{~g} / \mathrm{min}$

capillary column and flame ionisation detector (FID) and thermal conductivity detector (TCD). The FID was used to quantify hydrocarbon mole fractions, and the TCD was used to measure the concentration of hydrogen.

After the experiment was complete, the liquid that had accumulated in the trap was weighed and two liquid samples were analysed, also with the gas chromatograph. Representative liquid and gas product compositions were determined using the averages of these individual samples. Custom-made mixtures of the reactant and major products, obtained from Sigma-Aldrich, were used to calibrate the gas chromatography analyses.

The mass of dodecane fed and mass of liquid collected were both measured directly using an Ohaus Dec-O-Gram balance. The mass of gaseous product was simply set equal to the mass of dodecane fed minus the mass of liquid product. The mass of gaseous product was also measured independently using rotameters (calibrated using pure nitrogen), and the experiment was only considered valid if the mass balance closed within the uncertainty of the instruments, summarized in Table 1.

After each experiment, the system was flushed with pure nitrogen. No hydrocarbons were ever detected in the purge gas, nor was any other evidence ever found of material deposited on the walls of the reactor or in transfer lines.

\subsection{Experimental results}

Fig. 2 presents measurements of the conversion of $n$-dodecane with residence time at 950,1000 and $1050 \mathrm{~K}$ and shows that the reaction rate strongly increases with temperature.

Fig. 3 displays the formations of products vs. residence time at $1050 \mathrm{~K}$. The analyses of products have shown the formation of alkanes, mainly methane and ethane (Fig. 3a). The full range of 1-alkenes (Fig. 3b-d), from ethylene, which is the major carbon-containing product, to 1-decene, has been detected. Lower amounts of acetylene (Fig. 3a), allene, 1,3-butadiene (Fig. 3b) and 1,5-hexadiene have also been observed (Fig. 3c).

\section{Detailed kinetic model of the thermal decomposition of $\boldsymbol{n}$-dodecane}

The detailed kinetic model has been constructed by using a software package, EXGAS, which performs an automatic generation of mechanisms. This software has been mainly developed and tested to model the oxidation of alkanes [9-12] from 550 to $1250 \mathrm{~K}$, but it has been recently used to produce a mechanism for the low temperature (below $700 \mathrm{~K}$ ) 


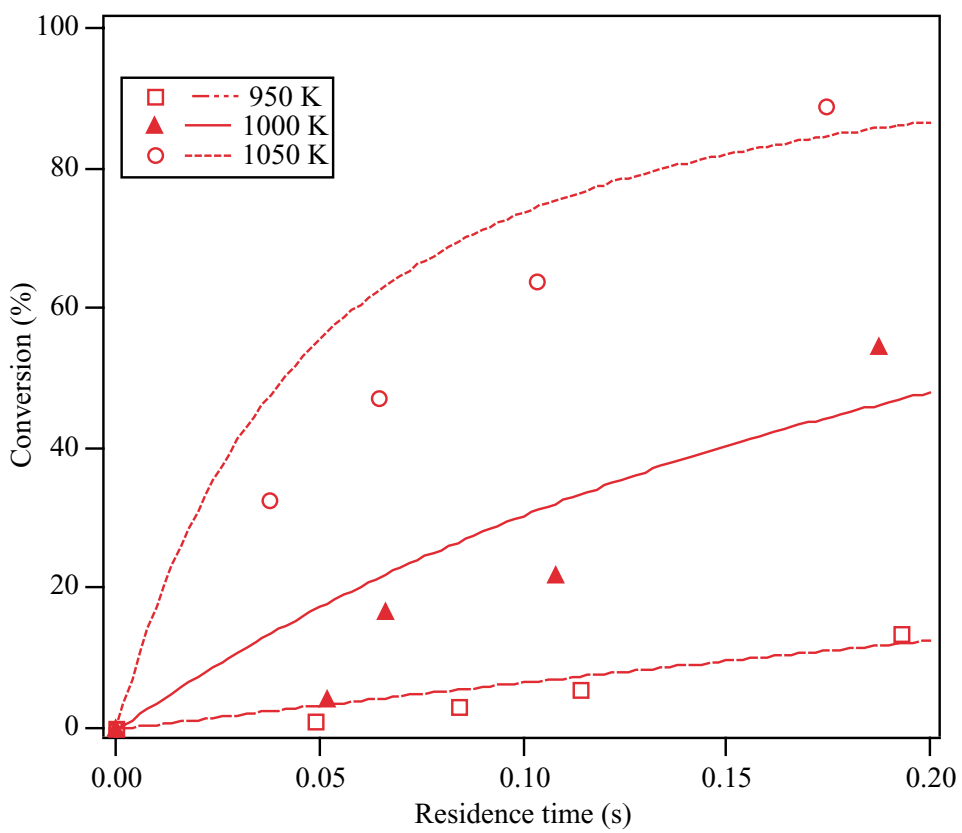

Fig. 2. Experimental and computed conversion of $n$-dodecane vs. residence time at 950,1000 and $1050 \mathrm{~K}$ in a plug flow reactor. Symbols are experimental results and curves simulations.

pyrolysis of $n$-tetradecane [13]. We describe here the changes, which have been needed to obtain a satisfactory model for the thermal decomposition of $n$-dodecane from 400 to $1500 \mathrm{~K}$. Specific heats, standard enthalpies of formation and entropies of all the considered molecules or free radicals are calculated using a software (THERGAS) [14] based on group and bond additivity methods proposed by Benson [15]. During the generation of the mechanism, the thermochemical data for every molecule or free radical are calculated automatically and written in the generated mechanism file which is used to run the simulations. According to the CHEMKIN II formalism, the thermochemical data are stored as 14 polynomial coefficients [16]. For the lumped molecules used in the secondary mechanism, the thermochemical data are those of the first molecule of the "family" which appears during the generation. Because thermochemical data for isomers, which include the same functional groups and rings of same size, are very close, this approximation will lead to negligible errors. That is the basis of the group additivity method proposed by Benson [15].

The system of generation (EXGAS) provides reaction mechanisms made of three parts:

\section{1. $A C_{0}-C_{6}$ reaction base}

This reaction base includes all the reactions involving radicals or molecules containing less than three carbon atoms $\left(\mathrm{C}_{0}-\mathrm{C}_{2}\right.$ reaction base [17]) and the reactions of $\mathrm{C}_{3}-\mathrm{C}_{4}$ unsaturated hydrocarbons [18], such as propyne, allene or butadienes, including reactions leading 


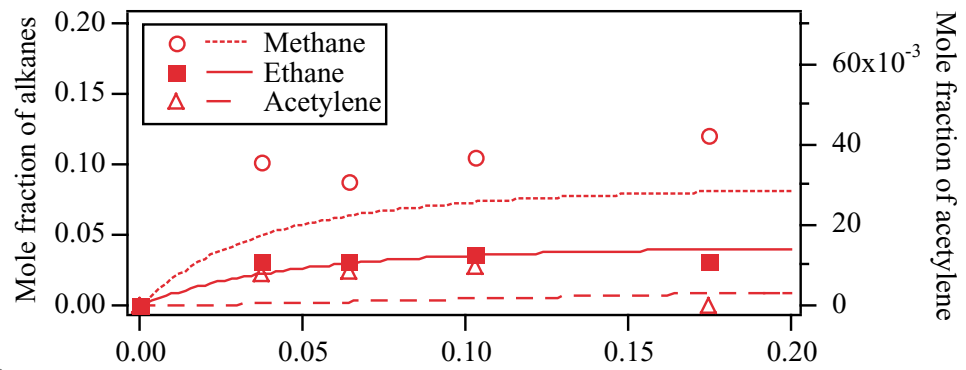

(a)

Residence time (s)

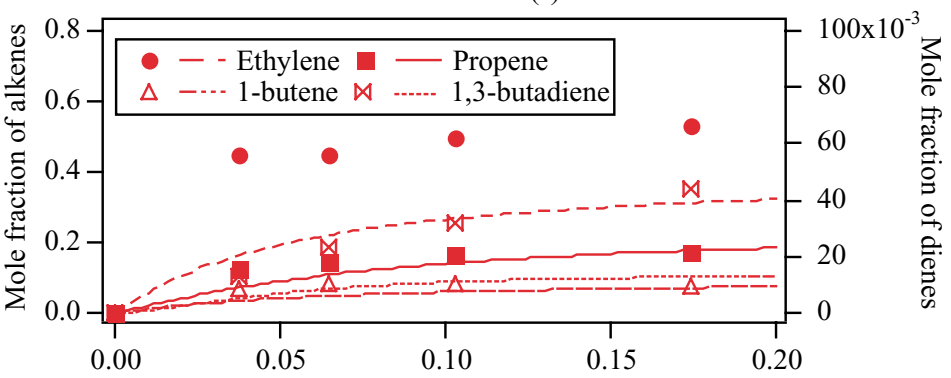

(b) Residence time (s)

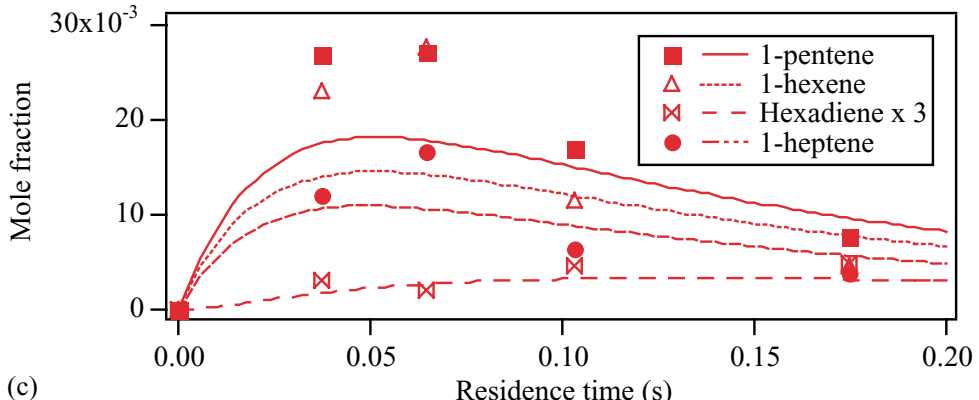

(c)

Residence time (s)

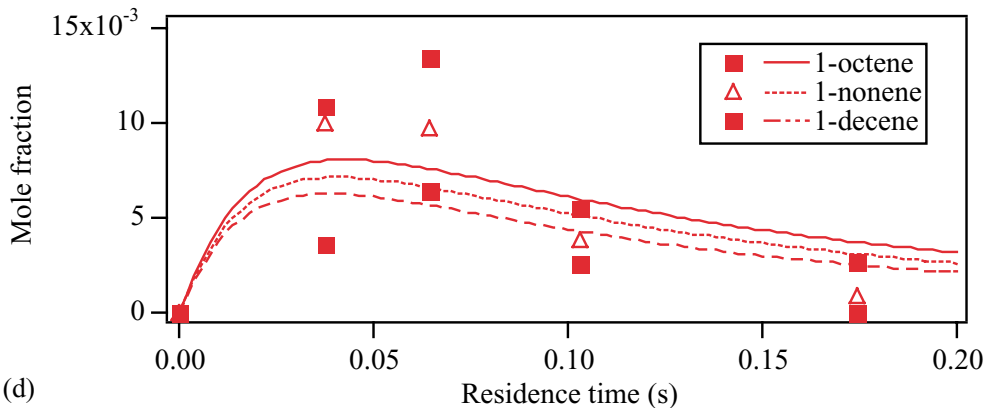

Fig. 3. Experimental and computed formation of products during the pyrolysis of $n$-dodecane vs. residence time at $1050 \mathrm{~K}$ in a plug flow reactor. Symbols are experimental results and curves simulations. 
to the formation of benzene. The kinetic data used in these reaction bases were taken from the literature. Values recommended by Baulch et al. [19] and Tsang et al. [20] are mainly used in the $\mathrm{C}_{0}-\mathrm{C}_{2}$ reaction base; the pressure-dependent rate constants follow the formalism proposed by Troe [21]. This $\mathrm{C}_{0}-\mathrm{C}_{6}$ reaction base has been used here after removing all the species or reactions involving the presence of oxygen atoms.

\subsection{A comprehensive primary mechanism}

The only molecular reactant considered in this part of the mechanism is the initial organic compound, here $n$-dodecane. The primary mechanism includes only elementary steps. The primary mechanism includes:

- Unimolecular initiation by bond fission (e.g. $\mathrm{C}_{12} \mathrm{H}_{26} \Rightarrow{ }^{\bullet} \mathrm{CH}_{3}+{ }^{\bullet} \mathrm{C}_{11} \mathrm{H}_{23}$ ).

- Propagation by beta-scission decomposition (e.g. ${ }^{\bullet} \mathrm{C}_{3} \mathrm{H}_{7} \Rightarrow{ }^{\bullet} \mathrm{CH}_{3}+\mathrm{C}_{2} \mathrm{H}_{4}$ ).

- Propagation by isomerizations involving cyclic transition state (e.g. $\mathrm{CH}_{3} \mathrm{CH}_{2} \mathrm{CH}_{2} \mathrm{CH}_{2}$ $\mathrm{CH}_{2} \mathrm{CH}_{2} \bullet \mathrm{CH}_{3} \mathrm{CH}^{\bullet} \mathrm{CH}_{2} \mathrm{CH}_{2} \mathrm{CH}_{2} \mathrm{CH}_{3}$ ).

- Propagation by metathesis, or hydrogen abstraction, from the reactant (e.g. ${ }^{\bullet} \mathrm{H}+\mathrm{C}_{12} \mathrm{H}_{26} \Rightarrow$ $\mathrm{H}_{2}+{ }^{\cdot} \mathrm{C}_{12} \mathrm{H}_{25}$ ).

For linear alkanes, only primary (linked to a carbon atoms linked to three atoms of hydrogen) and secondary (linked to a carbon atoms linked to two atoms of hydrogen) alkylic atoms of hydrogen can be abstracted.

- Termination steps by combinations of two free radicals (e.g. $\mathrm{CH}_{3}{ }^{\bullet}+\mathrm{CH}_{3} \bullet \Rightarrow \mathrm{C}_{2} \mathrm{H}_{6}$ ).

The generation of this mechanism is performed using an algorithm warranting its comprehensiveness [8], that is to say, each time a free radical is created, it is systematically submitted to all the generic propagation reactions above described. The radicals of the $\mathrm{C}_{0}-\mathrm{C}_{2}$ reaction base, such as ${ }^{\bullet} \mathrm{H}, \mathrm{CH}_{3}{ }^{\bullet}, \mathrm{C}_{2} \mathrm{H}_{5}{ }^{\bullet}, \mathrm{C}_{2} \mathrm{H}_{3}{ }^{\bullet}, \mathrm{C}_{2} \mathrm{H}^{\bullet}$, are also involved in propagation steps by metathesis and in the termination steps by combinations of two free radicals.

Rate coefficients for the isomerization of free radicals, the recombinations of free radicals and the unimolecular decomposition of molecules are calculated using the software (KINGAS) [22] based on Benson's thermochemical kinetics methods [15]. The rate constants of other reactions, which cannot be calculated by KINGAS, are estimated by means of correlations presented in Table 2.

For the isomerization of free radicals, Arrhenius pre-exponential factors $(A)$ are mainly based on the changes in the number of internal rotations as the reactant moves to the transition state [9]. Activation energies for isomerization reactions are set equal to the sum of the activation energy for $\mathrm{H}$-abstraction from the substrate by analogous radicals and the strain energy of the cyclic transition state $[9,22]$. Activation energies for the abstraction of $\mathrm{H}$ by ${ }^{\bullet} \mathrm{R}$ are taken to equal $46.0 \mathrm{~kJ} / \mathrm{mol}$ (secondary $\mathrm{H}$ ) and $56.4^{\bullet} \mathrm{kJ} / \mathrm{mol}$ (primary H). Strain energies of the cyclic transition state are taken to equal $26.3^{\circ} \mathrm{kJ} / \mathrm{mol}$ (for a five membered ring), $4.2^{\bullet} \mathrm{kJ} / \mathrm{mol}$ (for a six membered ring), $26.7^{\circ} \mathrm{kJ} / \mathrm{mol}$ (for a seven membered ring) and $43.3^{\circ} \mathrm{kJ} / \mathrm{mol}$ (for a height membered ring) according to Benson [15]. The rate constants for unimolecular decompositions are obtained from the data on the reverse reactions, i.e. recombinations, including thermochemical data calculated using the THERGAS software [14]. Activation energies for every recombination are taken to be zero. For the recombination 
Table 2

Quantitative structure-reactivity relationships

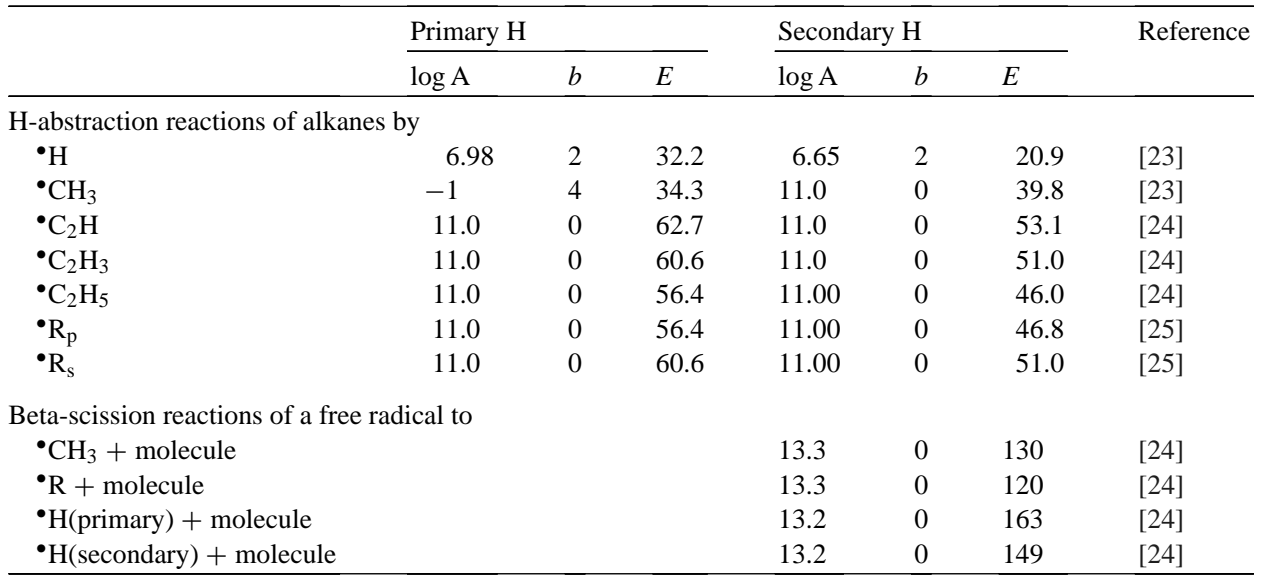

Rate constants are expressed in the form $k=A T^{b} \exp (-E / R T)$, with the units $\mathrm{cm}^{3}, \mathrm{~mol}, \mathrm{~s}, \mathrm{~kJ}$, by $\mathrm{H}$ atoms which can be abstracted. ${ }^{\bullet} \mathrm{R}_{\mathrm{p}}$ and ${ }^{\bullet} \mathrm{R}_{\mathrm{s}}$ are primary and secondary alkyl free radicals.

of two free radicals, the pre-exponential factor is estimated from modified collision theory $[9,15]$.

\subsection{A secondary mechanism}

This part of the mechanism describes the consumption of the products formed in the primary, that do not react in the reaction base $\left(\mathrm{C}_{0}-\mathrm{C}_{6}\right)$. To be able to model the chemistry of the products formed during the thermal decomposition at high temperature of an organic molecule, it is necessary to add a "secondary" mechanism to the comprehensive primary mechanism. An exponential increase of the size of the mechanism generated would result if the primary mechanism method described above were applied to all products. To reduce the number of reactants in the secondary reactions, which are the molecular products of the primary mechanism, a lumping of these primary molecules is achieved according to the following rules. Molecules that have the same molecular formula, the same functional groups and include rings of the same size, are lumped into one unique species, without distinguishing between isomers. The reactions of the lumped molecules, produced in the primary mechanism, are not strictly elementary steps, but global reactions. The "secondary" mechanism linked with the $\mathrm{C}_{0}-\mathrm{C}_{6}$ reaction base is then really a " $n$-ary" mechanism.

The two types of products obtained in the primary mechanism of the pyrolysis of $n$-dodecane are smaller alkanes and alkenes.

\subsubsection{Secondary reactions of alkanes}

Alkanes are formed in the primary mechanism by consecutive propagation steps: first, a beta scission, producing an alkyl radical smaller than $\mathrm{C}_{12}$, followed by metathesis with the reactant $\mathrm{C}_{12}$, forming a saturated hydrocarbon product and a $\mathrm{C}_{12}$ radical. At low tem- 
perature, due to the low value of their rate constants, the secondary reactions of alkanes are very slow [13], while, at high temperature, only low amounts of these compounds are formed. Their secondary reaction is then the following globalized reaction, which starts by a metathesis followed by subsequent decompositions by beta-scission of the alkyl radicals obtained:

$$
\mathrm{RH}+{ }^{\bullet} \mathrm{R}^{\prime} \rightarrow \mathrm{R}^{\prime} \mathrm{H}+\bullet \mathrm{R}^{\prime \prime}+x \mathrm{C}_{2} \mathrm{H}_{4}
$$

where $\mathrm{RH}$ is an alkane $\mathrm{C}_{n} \mathrm{H}_{2 n+2}$ containing more than two atoms of carbon, ${ }^{\bullet} \mathrm{R}^{\prime}$ is ${ }^{\bullet} \mathrm{H}$, ${ }^{\bullet} \mathrm{CH}_{3},{ }^{\bullet} \mathrm{C}_{2} \mathrm{H}_{5},{ }^{\bullet} \mathrm{C}_{3} \mathrm{H}_{7}$ or ${ }^{\bullet} \mathrm{C}_{4} \mathrm{H}_{9}, \mathrm{R}^{\prime} \mathrm{H}$ is $\mathrm{H}, \mathrm{CH}_{4}, \mathrm{C}_{2} \mathrm{H}_{6}, \mathrm{C}_{3} \mathrm{H}_{8}$ or $\mathrm{C}_{4} \mathrm{H}_{10},{ }^{\bullet} \mathrm{R}^{\prime \prime}$ is ${ }^{\bullet} \mathrm{CH}_{3}$ if $n$ is even or ${ }^{\bullet} \mathrm{C}_{2} \mathrm{H}_{5}$ if $n$ is odd.

The rate constants of these lumped reactions are derived from those used for the metathesis in the primary mechanism considering that an average of six secondary alkylic atoms of hydrogen can be abstracted for each considered molecules. We have then (with $R$ the gas constant in $\mathrm{kJ} \mathrm{mol}^{-1}$ ):

- $k=2.7 \times 10^{7} \times T^{2} \exp (-20.9 / R T) \mathrm{cm}^{3} \mathrm{~mol}^{-1} \mathrm{~s}^{-1}$, when $\bullet \mathrm{R}$ is $\bullet \mathrm{H}$,

- $k=6.0 \times 10^{11} \exp (-39.8 / R T) \mathrm{cm}^{3} \mathrm{~mol}^{-1} \mathrm{~s}^{-1}$, when ${ }^{\bullet} \mathrm{R}$ is ${ }^{\bullet} \mathrm{CH}_{3}$,

- $k=6.0 \times 10^{11} \exp (-46.0 / R T) \mathrm{cm}^{3} \mathrm{~mol}^{-1} \mathrm{~s}^{-1}$, when ${ }^{\bullet} \mathrm{R}$ is ${ }^{\bullet} \mathrm{C}_{2} \mathrm{H}_{5},{ }^{\bullet} \mathrm{C}_{3} \mathrm{H}_{7}$ or ${ }^{\bullet} \mathrm{C}_{4} \mathrm{H}_{9}$.

\subsubsection{Secondary reactions of alkenes and dienes}

In the case of the long linear molecule of $n$-dodecane, the primary mechanism leads to the formation of 1-alkenes by decomposition of alkyl free radicals. The secondary reactions of alkenes are important because they can react relatively easily at low temperature and they are the major formed products at high temperature. Without being as comprehensive as the primary mechanism (i.e. without distinguishing the different possible radical isomers), the secondary mechanism of alkenes should then be considered with much details.

The reactions considered here for alkene consumption are: unimolecular initiations, additions to the double bond, $\mathrm{H}$-abstractions, retro-ene reactions and combinations of allylic free radicals.

3.3.2.1. Unimolecular initiations. Due of their relatively low activation energy (approximately $290 \mathrm{~kJ} / \mathrm{mol}$ ), only unimolecular initiations leading to the formation of allyl radical $\left({ }^{\bullet} \mathrm{C}_{3} \mathrm{H}_{5}\right)$ have been considered. The reactions of the obtained alkyl radicals are already considered in the primary mechanism. The kinetic parameters used have been estimated using the software KINGAS [22].

3.3.2.2. Additions. Two types of addition are considered, "low temperature" additions for dodecyl radicals, which are the most abundant at low temperature [13], and "high temperature" additions for ${ }^{\bullet} \mathrm{H},{ }^{\bullet} \mathrm{CH}_{3}$ and ${ }^{\bullet} \mathrm{C}_{2} \mathrm{H}_{5}$ radicals.

Low temperature additions. The addition of a dodecyl radical to an alkene produces a secondary alkyl radical, containing more than 12 atoms of carbon, which can react by metathesis with $n$-dodecane. Without distinguishing to which side of the double bond the addition occurs, we have then the two globalized reactions: 
- $\mathrm{C}_{n} \mathrm{H}_{2 n}+{ }^{\bullet} \mathrm{C}_{12} \mathrm{H}_{25} \rightarrow{ }^{\bullet} \mathrm{C}_{12+n} \mathrm{H}_{25+2 n}$, with $k=9.6 \times 10^{10} \exp (-33.4 / R T) \mathrm{cm}^{3} \mathrm{~mol}^{-1} \mathrm{~s}^{-1}$ [13],

- ${ }^{\bullet} \mathrm{C}_{12+n} \mathrm{H}_{25+2 n}+\mathrm{C}_{12} \mathrm{H}_{26} \rightarrow{ }^{\bullet} \mathrm{C}_{12} \mathrm{H}_{25}+\mathrm{C}_{12+n} \mathrm{H}_{25+2 n+1}$, with $k$ deduced from Table 1, where $\mathrm{C}_{n} \mathrm{H}_{2 n}$ is every considered alkene.

High temperature additions. The addition of ${ }^{\bullet} \mathrm{H},{ }^{\bullet} \mathrm{CH}_{3}$ and ${ }^{\bullet} \mathrm{C}_{2} \mathrm{H}_{5}$ radicals produces alkyl radicals, which can decompose by beta-scissions. Depending on which side of the double bond the addition occurs, we have then the following globalized reactions:

If the addition occurs on the first atom of carbon of the chain:

- $\mathrm{C}_{n} \mathrm{H}_{2 n}+{ }^{\bullet} \mathrm{H} \rightarrow \mathrm{C}_{3} \mathrm{H}_{6}+x \mathrm{C}_{2} \mathrm{H}_{4}+\bullet$ R, with $k=7.2 \times 10^{12} \exp (-5.4 / R T) \mathrm{cm}^{3} \mathrm{~mol}^{-1} \mathrm{~s}^{-1}$ [26],

- $\mathrm{C}_{n} \mathrm{H}_{2 n}+{ }^{\bullet} \mathrm{CH}_{3} \rightarrow \mathrm{C}_{4} \mathrm{H}_{8}+x \mathrm{C}_{2} \mathrm{H}_{4}+\bullet$ R, with $k=1.7 \times 10^{11} \exp (-30.9 / R T) \mathrm{cm}^{3} \mathrm{~mol}^{-1} \mathrm{~s}^{-1}$ [26],

- $\mathrm{C}_{n} \mathrm{H}_{2 n}+{ }^{\bullet} \mathrm{C}_{2} \mathrm{H}_{5} \rightarrow \mathrm{C}_{5} \mathrm{H}_{10}+x \mathrm{C}_{2} \mathrm{H}_{4}+\bullet R$, with $k=1.7 \times 10^{11} \exp (-30.9 / R T) \mathrm{cm}^{3} \mathrm{~mol}^{-1} \mathrm{~s}^{-1}$ [26].

where $\mathrm{C}_{n} \mathrm{H}_{2 n}$ is an alkene containing at least four atoms of carbon, ${ }^{\bullet} \mathrm{R}$ is ${ }^{\bullet} \mathrm{CH}_{3}$ if $n$ is even and ${ }^{\bullet} \mathrm{C}_{2} \mathrm{H}_{5}$ if $n$ is odd.

If the addition occurs on the second atom of carbon of the chain:

- $\mathrm{C}_{n} \mathrm{H}_{2 n}+\bullet \mathrm{H} \rightarrow x \mathrm{C}_{2} \mathrm{H}_{4}+\bullet R$, with $k=7.2 \times 10^{12} \exp (-12.1 / R T) \mathrm{cm}^{3} \mathrm{~mol}^{-1} \mathrm{~s}^{-1}$ [26],

- $\mathrm{C}_{n} \mathrm{H}_{2 n}+{ }^{\bullet} \mathrm{CH}_{3} \rightarrow \mathrm{C}_{3} \mathrm{H}_{6}+x \mathrm{C}_{2} \mathrm{H}_{4}+\bullet R$, with $k=9.6 \times 10^{10} \exp (-33.4 / R T) \mathrm{cm}^{3} \mathrm{~mol}^{-1} \mathrm{~s}^{-1}$ [26],

- $\mathrm{C}_{n} \mathrm{H}_{2 n}+{ }^{\bullet} \mathrm{C}_{2} \mathrm{H}_{5} \rightarrow \mathrm{C}_{4} \mathrm{H}_{8}+x \mathrm{C}_{2} \mathrm{H}_{4}+{ }^{\bullet} R$, with $k=9.6 \times 10^{10} \exp (-33.4 / R T) \mathrm{cm}^{3} \mathrm{~mol}^{-1} \mathrm{~s}^{-1}$ [26].

where $\mathrm{C}_{n} \mathrm{H}_{2 n}$ is an alkene containing at least four atoms of carbon, ${ }^{\bullet} \mathrm{R}$ is ${ }^{\bullet} \mathrm{CH}_{3}$ if $n$ is even and ${ }^{\bullet} \mathrm{C}_{2} \mathrm{H}_{5}$ if $n$ is odd.

3.3.2.3. Abstraction of hydrogen atoms. Only the abstractions of alkylic and allylic (linked to an atom of carbon next to the double bond) atoms of hydrogen have been considered; the abstractions of vinylic (linked to an atom of carbon on the double bond) atoms of hydrogen, which are more difficult, have been neglected.

Abstraction of allylic hydrogen atoms. The abstraction of an allylic $\mathrm{H}$-atom leads to the formation of a resonance-stabilised radical and consequently these abstractions have lower activation energies. This resonance stabilised radical can undergo termination reactions with radicals such as ${ }^{\bullet} \mathrm{H},{ }^{\bullet} \mathrm{CH}_{3}$ or other allylic radicals, or can decompose by $\beta$-scissions to give 1,3-butadiene and an alkyl free radical, which can in turn decompose by further beta-scissions. For the latter case, we have the globalized reactions:

- $\mathrm{C}_{n} \mathrm{H}_{2 n}+{ }^{\bullet} \mathrm{H} \rightarrow \mathrm{H}_{2}+1,3-\mathrm{C}_{4} \mathrm{H}_{6}+x \mathrm{C}_{2} \mathrm{H}_{4}+\bullet$ R, with $k=5.4 \times 10^{4} \times T^{2.5} \exp (7.9 / R T)$ $\mathrm{cm}^{3} \mathrm{~mol}^{-1} \mathrm{~s}^{-1}$,

- $\mathrm{C}_{n} \mathrm{H}_{2 n}+{ }^{\bullet} \mathrm{CH}_{3} \rightarrow \mathrm{CH}_{4}+1,3-\mathrm{C}_{4} \mathrm{H}_{6}+x \mathrm{C}_{2} \mathrm{H}_{4}+\bullet$ R, with $k=1.0 \times 10^{11} \exp (-30.9 / R T)$ $\mathrm{cm}^{3} \mathrm{~mol}^{-1} \mathrm{~s}^{-1}$, 
- $\mathrm{C}_{n} \mathrm{H}_{2 n}+{ }^{\bullet} \mathrm{C}_{2} \mathrm{H}_{5} \rightarrow \mathrm{C}_{2} \mathrm{H}_{6}+1,3-\mathrm{C}_{4} \mathrm{H}_{6}+x \mathrm{C}_{2} \mathrm{H}_{4}+\cdot{ }^{\bullet} \mathrm{R}$, with $k=2.0 \times 10^{2.2} \times$ $T^{3.5} \exp (-30.9 / R T) \mathrm{cm}^{3} \mathrm{~mol}^{-1} \mathrm{~s}^{-1}$.

where $\mathrm{C}_{n} \mathrm{H}_{2 n}$ is an alkene containing more than four atoms of carbon, ${ }^{\bullet} \mathrm{R}$ is ${ }^{\bullet} \mathrm{CH}_{3}$ if $n$ is even and ${ }^{\bullet} \mathrm{C}_{2} \mathrm{H}_{5}$ if $n$ is odd.

The rate constants for the abstraction of two secondary allylic $\mathrm{H}$ atoms are deduced from the values proposed by Tsang [26] for propene by assuming the same difference, for the $A$ factors and the activation energies, between primary and secondary $\mathrm{H}$ atoms as in the case of alkylic $\mathrm{H}$ atoms.

Abstraction of alkylic hydrogen atoms. In the case of long linear alkenes, these H-abstractions play a significant role and explain the formation of specific products experimentally observed such as diolefins (for example $\mathrm{C}_{5} \mathrm{H}_{8}$ ). The reactions included in the kinetic scheme derive from an analysis of the detailed reactions of linear 1-alkenes performed in the case of the oxidation of $n$-hexadecane at high temperature [27] and are summarized in Table 3 with the example of the reaction of $\mathrm{C}_{10} \mathrm{H}_{20}$.

The abstraction of an alkylic $\mathrm{H}$-atom leads to an alkenyl radical. In the temperature range $1000-1200 \mathrm{~K}$, this alkenyl radical reacts according to two main pathways: isomerization and $\beta$-scission.

Alkenyl radical isomerization gives a resonance-stabilized free radical (allylic radical). The fastest isomerizations are those involving a cyclic transition state containing five or six atoms [28]. At $1050 \mathrm{~K}$, the isomerization of an alkenyl radical to give an allylic radical is 5-10 times faster than $\beta$-scission, according to the estimates produced in this model. Consequently, if the alkenyl free radical obtained by $\mathrm{H}$-abstraction can isomerize via a cyclic transition state containing five or six atoms, the formation of an allylic radical is

Table 3

Secondary mechanism of alkenes: detailed reactions and rate constants for abstractions of alkylic $\mathrm{H}$ atoms $[23,24]$

\begin{tabular}{|c|c|}
\hline Type of abstraction & Example: $\mathrm{C}_{10} \mathrm{H}_{20}$ \\
\hline$(\mathrm{A}) \cdot \mathrm{R}+\mathrm{C}_{n} \mathrm{H}_{2 n} \rightarrow \mathrm{RH}+1,3-\mathrm{C}_{4} \mathrm{H}_{6}+{ }^{\bullet} \mathrm{C}_{i} \mathrm{H}_{2 i+1}$ & $\begin{array}{l}\cdot \mathrm{R}+\mathrm{C}_{10} \mathrm{H}_{20} \rightarrow \mathrm{RH}+1,3-\mathrm{C}_{4} \mathrm{H}_{6}+\cdot 1-\mathrm{C}_{6} \mathrm{H}_{13} \\
\text { (4 secondary } H \text { atoms involved) }\end{array}$ \\
\hline (B) ${ }^{\bullet} \mathrm{R}+\mathrm{C}_{n} \mathrm{H}_{2 n} \rightarrow \mathrm{RH}+\mathrm{C}_{m} \mathrm{H}_{2 m-2}+{ }^{\bullet} \mathrm{C}_{i} \mathrm{H}_{2 i+1}$ & 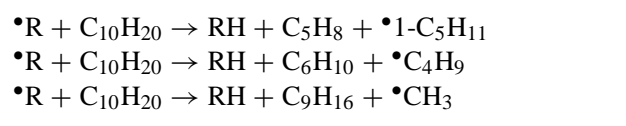 \\
\hline $\begin{array}{c}(\mathrm{C}) \cdot \mathrm{R}+\mathrm{C}_{n} \mathrm{H}_{2 n} \rightarrow \mathrm{RH}+\mathrm{C}_{m} \mathrm{H}_{2 m}+{ }^{\bullet} \mathrm{C}_{3} \mathrm{H}_{5} \\
\quad \cdot \mathrm{R}+\mathrm{C}_{n} \mathrm{H}_{2 n} \rightarrow \mathrm{RH}+\mathrm{C}_{m} \mathrm{H}_{2 m}+{ }^{\bullet} \mathrm{C}_{2} \mathrm{H}_{3}\end{array}$ & $\begin{array}{l}\cdot \mathrm{R}+\mathrm{C}_{10} \mathrm{H}_{20} \rightarrow \mathrm{RH}+1-\mathrm{C}_{8} \mathrm{H}_{16}+{ }^{\bullet} \mathrm{C}_{2} \mathrm{H}_{3} \\
\cdot \mathrm{R}+\mathrm{C}_{10} \mathrm{H}_{20} \rightarrow \mathrm{RH}+1-\mathrm{C}_{7} \mathrm{H}_{14}+{ }^{\bullet} \mathrm{C}_{3} \mathrm{H}_{5}\end{array}$ \\
\hline (D) $\begin{aligned} & \bullet \mathrm{R}+\mathrm{C}_{n} \mathrm{H}_{2 n} \rightarrow \mathrm{RH}+\mathrm{C}_{m} \mathrm{H}_{2 m}+1,3-\mathrm{C}_{4} \mathrm{H}_{6} \\
& +{ }^{\bullet} \mathrm{C}_{i} \mathrm{H}_{2 i+1}\end{aligned}$ & $\begin{array}{l}\cdot \mathrm{R}+\mathrm{C}_{10} \mathrm{H}_{20} \rightarrow \mathrm{RH}+\mathrm{C}_{4} \mathrm{H}_{8}+1,3-\mathrm{C}_{4} \mathrm{H}_{6}+\cdot \mathrm{C}_{2} \mathrm{H}_{5} \\
\cdot \mathrm{R}+\mathrm{C}_{10} \mathrm{H}_{20} \rightarrow \mathrm{RH}+\mathrm{C}_{3} \mathrm{H}_{6}+1,3-\mathrm{C}_{4} \mathrm{H}_{6}+\cdot 1-\mathrm{C}_{3} \mathrm{H}_{7} \\
\cdot \mathrm{R}+\mathrm{C}_{10} \mathrm{H}_{20} \rightarrow \mathrm{RH}+\mathrm{C}_{2} \mathrm{H}_{4}+1,3-\mathrm{C}_{4} \mathrm{H}_{6}+\cdot 1-\mathrm{C}_{4} \mathrm{H}_{9} \\
\text { (3 primary H atoms involved) }\end{array}$ \\
\hline
\end{tabular}

(E) $\bullet \mathrm{R}+\mathrm{C}_{n} \mathrm{H}_{2 n} \rightarrow \mathrm{RH}+\mathrm{C}_{m} \mathrm{H}_{2 m}+1,3-\mathrm{C}_{4} \mathrm{H}_{6}$ $+x \mathrm{C}_{2} \mathrm{H}_{4}+{ }^{\bullet} \mathrm{C}_{i} \mathrm{H}_{2 i+1}(n>10)$

The radical ${ }^{\bullet} \mathrm{R}$ is ${ }^{\bullet} \mathrm{H},{ }^{\bullet} \mathrm{CH}_{3}$ or ${ }^{\bullet} \mathrm{C}_{2} \mathrm{H}_{5} ; \mathrm{C}_{m} \mathrm{H}_{2 m}$ are lower 1-alkenes and $\mathrm{C}_{m} \mathrm{H}_{2 m-2}$ are dienes, which react also in the secondary mechanism. The reactions of the alkylic ${ }^{\bullet} \mathrm{C}_{i} \mathrm{H}_{2 i+1}$ radicals are included in the primary mechanism. The rate constants for alkylic metatheses derived from those presented in Table 1. 
written. This allylic radical is decomposed by $\beta$-scission into 1,3-butadiene and an alkyl radical, which reacts in the primary mechanism (reaction A in Table 3 ).

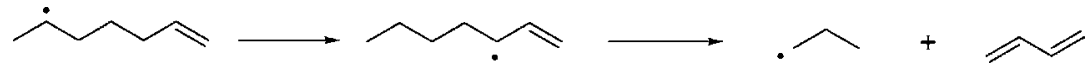

If an isomerization of the alkenyl radical is not possible, a $\beta$-scission of a $\mathrm{C}-\mathrm{C}$ bond occurs giving an alkyl radical and a diolefin (reaction 3) or an 1-alkene and a smaller alkenyl radical (reaction 4). For instance, the alkenyl radical $3-\mathrm{C}_{11} \mathrm{H}_{21}$ can react as follows:

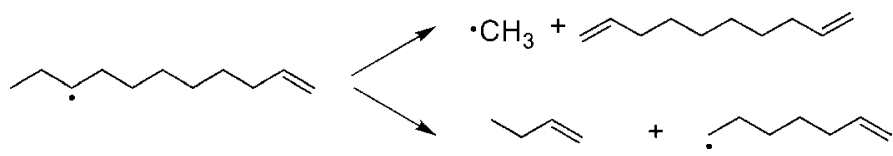

These reactions (reactions B, C, D and E in Table 3) form dienes and 1-alkenes, which in turn reacts in the secondary mechanism according to the rules previously described.

3.3.2.4. Retro-ene reactions. A retro-ene reaction is a 1,5-hydrogen shift reaction followed by dissociation [29-31]. The detailed mechanism of these reactions has been discussed and structures of the transition state have been explored [29]. For example in the case of 1-heptene, the transition state can be represented as follows:

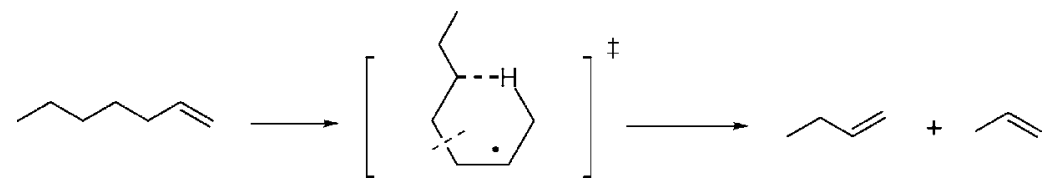

In the case of linear 1-alkenes, the products formed are propene and lower 1-alkenes and the following globalized reactions have been considered:

$\mathrm{C}_{n} \mathrm{H}_{2 n} \rightarrow \mathrm{C}_{3} \mathrm{H}_{6}+\mathrm{C}_{n-3} \mathrm{H}_{2(n-3)}, k=8.0 \times 10^{12} \exp (-236 / R T) \mathrm{cm}^{3} \mathrm{~mol}^{-1} \mathrm{~s}^{-1}$ [30], where $\mathrm{C}_{n} \mathrm{H}_{2 n}$ is an alkene containing at least five atoms of carbon.

3.3.2.5. Reactions of dienes. The reactions of 1,3-butadiene are included in the $\mathrm{C}_{3}-\mathrm{C}_{6}$ reaction base; the formations of other dienes are very weak. The dienes formed in the secondary mechanism can react in the same ways as 1-alkenes. We considered unimolecular initiations, additions of $\mathrm{H}$-atoms, $\mathrm{H}$-abstractions, and retro-ene reactions. The species formed are smaller 1-alkenes and dienes, which react again in the secondary mechanism.

\section{Comparison between experimental and computed results}

Simulations have been performed using CHEMKIN II software [16] using the above presented kinetic model. The primary mechanism involves 75 species and includes 475 reactions and the secondary mechanism involves 40 species and includes 467 reactions. Overall, the reaction scheme includes 1175 reactions involving 154 species. These were a priori predictions and no attempt was made to improve the agreement through parameter fitting. 
Figs. 1 and 2 present a comparison between the computed profiles and the experimental results presented here. The plug flow reactor has been modeled as a series of 100 perfectly stirred reactors using a home made software derived from the PSR software [16]. Despite the low values of the Reynolds numbers (in the range of 40-400) showing a laminar flow, the high diameter/length ratio of our reactor $(\approx 200)$ allowed us to model it as a plug flow reactor and to neglect the radial dispersion of concentrations and temperatures. The agreement obtained for the conversion vs. residence time of $n$-dodecane (Fig. 2) is satisfactory for the three temperatures. Concerning the formation of products, the agreement is satisfactory for alkanes, methane and ethane (Fig. 3a), for all the alkenes from propene to 1-decene (Fig. 3b-d), for acetylene (Fig. 3a) and for 1,5-hexadiene (Fig. 3c). The mole fraction of ethylene is under predicted by a factor 1.5 and that of 1,3-butadiene by a factor of almost 3 .

In order to check the validity of our mechanism in a wider range of conditions, we have tried to reproduce the other gas-phase experimental results published in the literature. Fig. 4 displays a comparison between the computed profiles and the experimental conversions obtained by Zhou et al. [4]. This study was performed at temperatures from 623 to $893 \mathrm{~K}$ and under atmospheric pressure in a stainless steel unpacked flow reactor, which has been modelled as a perfectly stirred reactor. It is worth noting that this reactor, which is not really a perfectly stirred reactor, can neither be considered as a plug flow reactor due to its wide diameter. Nevertheless, the agreement shown in Fig. 4 for the different conditions appears to be reasonable.

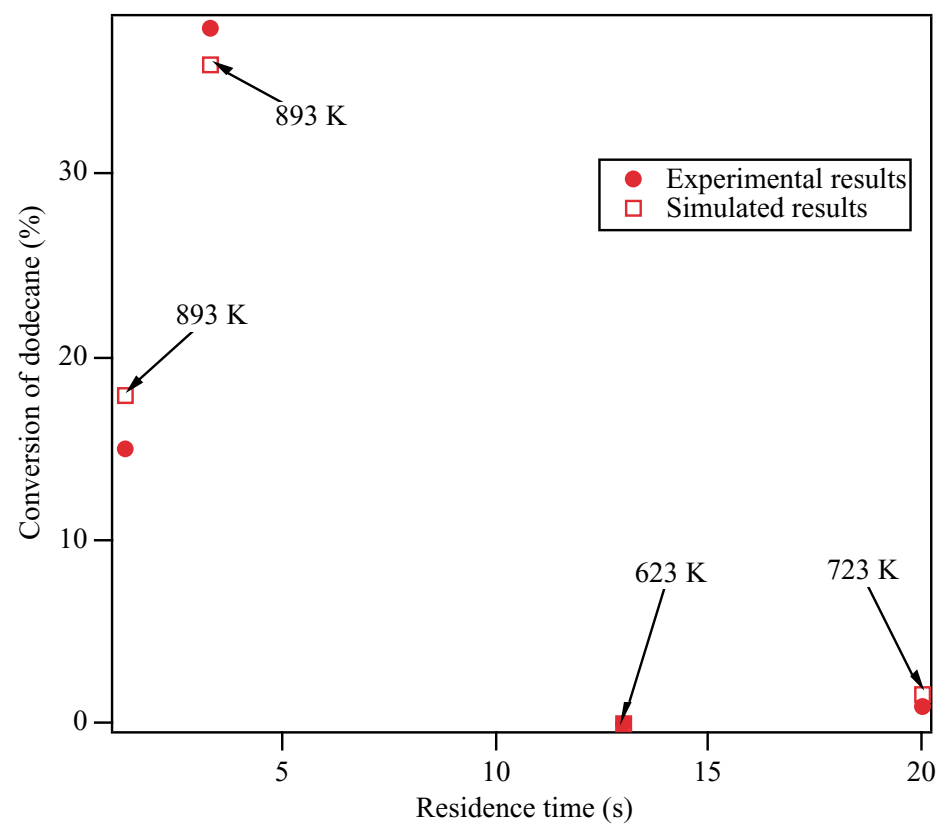

Fig. 4. Comparison between computed and experimental conversion of $n$-dodecane in a unpacked down flow reactor for different temperatures and residence times at $100 \mathrm{kPa}$ [1]. Symbols are experimental results and curves simulations. 


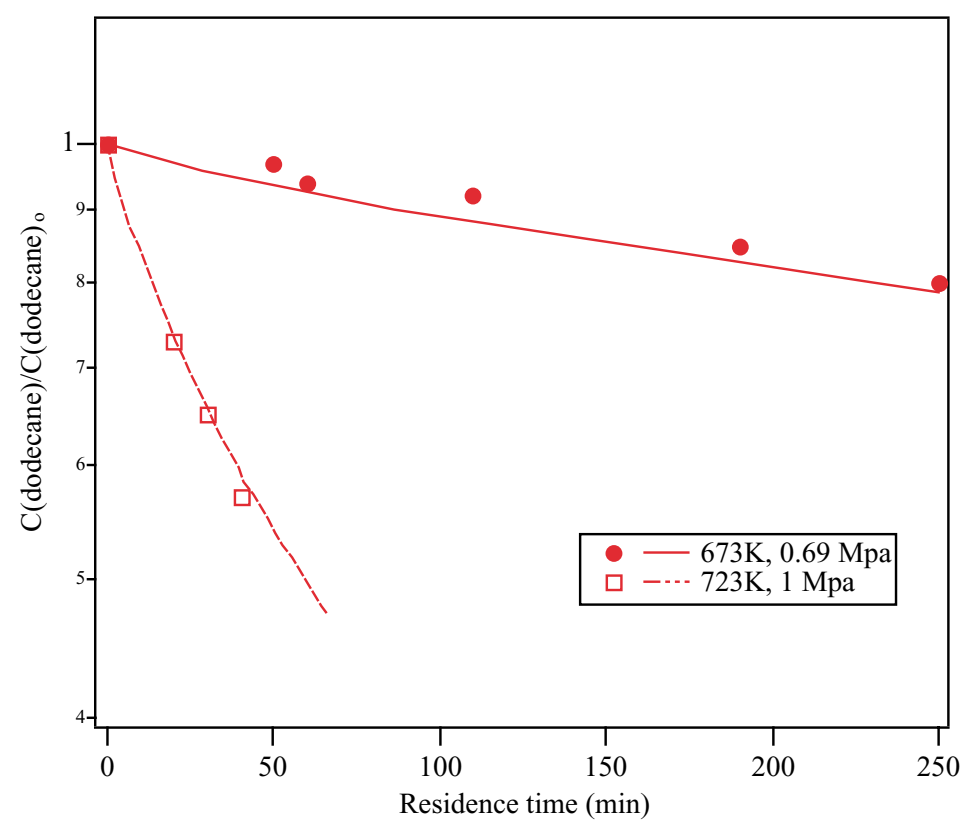

Fig. 5. Comparison between computed and experimental plot of $\mathrm{C}$ (dodecane)/C(dodecane $)_{0}$ obtained in a stainless steel static microreactor for pure $n$-dodecane $[2,3]$. Symbols are experimental results and curves simulations.

Fig. 5 shows a comparison between the computed profiles and the experimental results obtained by Yoon et al. [5,6] at temperatures from 673 to $723 \mathrm{~K}$ and pressures from 6.9 to 10 bar. The static stainless steel microreactors have been modelled as isothermal closed vessels using the SENKIN software [31]. Here also, the proposed mechanism allows the simulations to satisfactorily reproduce the experimental results. In the same way as Yoon et al. $[5,6]$, we have plotted the ratio between the remaining $n$-dodecane concentration at the given residence time $(\mathrm{C}($ dodecane $))$ and the initial alkane concentration $\left(\mathrm{C}(\text { dodecane })_{0}\right)$ using a semi-logarithmic scale. It is interesting to note that the curves computed with our detailed mechanism are not straight lines and that they cannot then be reproduced by an apparent first order kinetic expression as proposed by Yoon et al. [2,3]. This is not surprising as the order of a gas-phase hydrocarbon pyrolysis usually varies from 0.5 at about $673 \mathrm{~K}$ to 1.5 at about $723 \mathrm{~K}$ and can also change during the reaction course [31,32].

\section{Analysis of the mechanism}

A flow rate analysis performed in the conditions of Fig. 2, at a temperature of $1050 \mathrm{~K}$ and a residence time of $0.04 \mathrm{~s}$ ( $50 \%$ of conversion), shows that the main pathways consuming $n$-dodecane are unimolecular initiations (to give 1-alkyl radicals) for $10 \%$ and abstraction of hydrogen atoms with ${ }^{\bullet} \mathrm{H}$ atoms and ${ }^{\bullet} \mathrm{CH}_{3}$ radicals (to produce the six isomers of dodecyl radical) for $90 \%$. In these conditions, the rates of the abstractions of hydrogen atoms with 


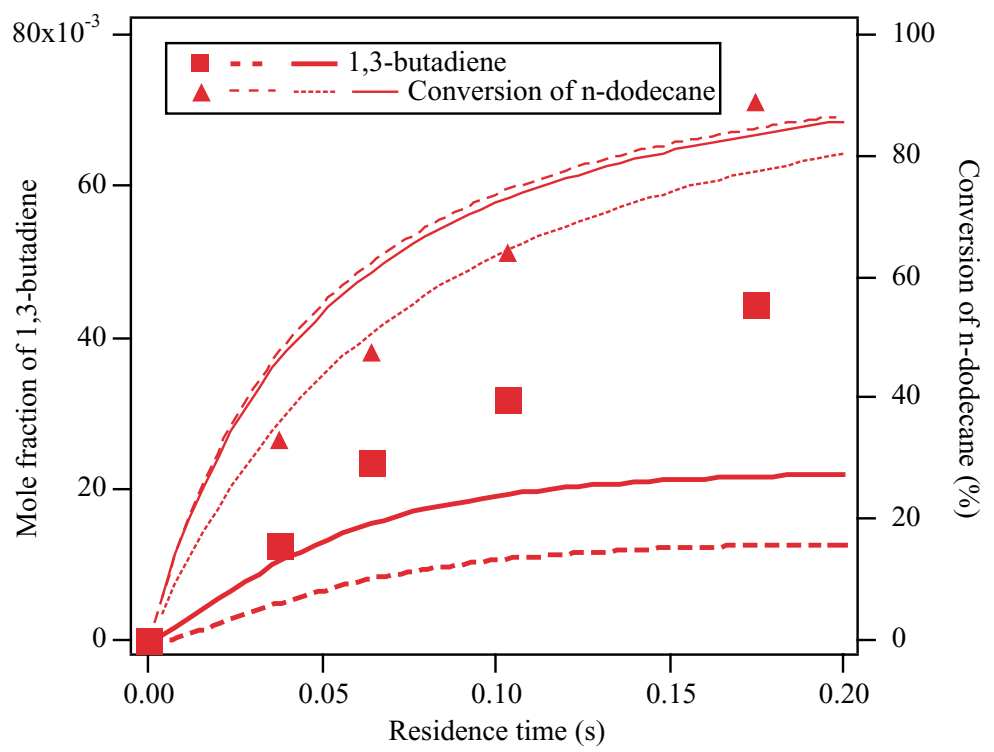

Fig. 6. Study of the influence of the abstractions of hydrogen atoms from $n$-dodecane by ${ }^{\bullet} \mathrm{CH}_{3}$ radicals (meth. $\left({ }^{\bullet} \mathrm{CH} 3\right)$ ) and of that of the abstractions of allylic hydrogen atoms from alkenes by ${ }^{\bullet} \mathrm{CH}_{3}$ and ${ }^{\bullet} \mathrm{C}_{2} \mathrm{H}_{5}$ radicals (Abstr. $\left({ }^{\bullet} \mathrm{CH}_{3}+{ }^{\bullet} \mathrm{C}_{2} \mathrm{H}_{5}\right)$ ). Symbols are experimental results, dashed curves are simulations with the unmodified mechanism, the dotted curve is simulation with a mechanism in which the rate constants of meth. $\left({ }^{\bullet} \mathrm{CH} 3\right)$ have been divided by a factor 5 and plain curves are simulation with a mechanism in which the rate constants of Abstr. $\left({ }^{\bullet} \mathrm{CH}_{3}+{ }^{\bullet} \mathrm{C}_{2} \mathrm{H}_{5}\right)$ have been multiplied by a factor 2 .

${ }^{\bullet} \mathrm{CH}_{3}$ radicals are similar to those with ${ }^{\bullet} \mathrm{H}$ atoms, due to the fact that the concentration of ${ }^{\bullet} \mathrm{CH}_{3}$ radicals is 300 times higher than that of ${ }^{\bullet} \mathrm{H}$ atoms.

Sensitivity analyses, performed at the conditions of Fig. 2, show that the reactions with the most influence on the conversion of $n$-dodecane are unimolecular decomposition and the abstractions of hydrogen atoms with ${ }^{\circ} \mathrm{CH}_{3}$ radicals in the primary mechanism. The sensitivity coefficients for the abstractions of hydrogen atoms with ${ }^{\bullet} \mathrm{H}$ atoms are very low. Fig. 6 shows that a decrease of the rate constants of the abstractions of hydrogen atoms from $n$-dodecane with ${ }^{\bullet} \mathrm{CH}_{3}$ radicals leads to a lower conversion of this reactant. The fact that the uncertainties of the rate constants of the abstraction of hydrogen atoms with ${ }^{\bullet} \mathrm{CH}_{3}$ radicals are much higher than those with ${ }^{\bullet} \mathrm{H}$ atoms can then explain some of the disagreement obtained between experiments and modelling.

The long 1-alkyl radicals (e.g. 1-dodecyl radicals) obtained react mainly by isomerization to give alkyl radicals with the radical center in another position; the formation of ethylene and a lower 1-alkyl radical accounts only for about $20 \%$ of the consumption of this long radical. Other alkyl radicals react mainly by $\beta$-scission to give 1 -alkyl radicals and alkenes. The rates of formation of alkanes other than methane and ethane are very low.

In these conditions, long alkenes react mainly by unimolecular initiations to give an allyl and a 1-alkyl radicals (13\% of the consumption of 1-octene), by abstractions of hydrogen atoms with ${ }^{\bullet} \mathrm{H}$ atoms and ${ }^{\bullet} \mathrm{CH}_{3}$ and ${ }^{\bullet} \mathrm{C}_{2} \mathrm{H}_{5}$ radicals (52\% of the consumption of 1-octene) 
leading to the production of 1,3-butadiene and other diolefins and by retro-ene reactions to produce lower alkenes and propene ( $35 \%$ of the consumption of 1-octene). The uncertainties of the rate constants of the abstraction of hydrogen atoms by ${ }^{\bullet} \mathrm{CH}_{3}$ and ${ }^{\circ} \mathrm{C}_{2} \mathrm{H}_{5}$ radicals likely explain the problem encountered to reproduce the formation of 1,3-butadiene. Fig. 6 shows that an increase of the rate constants of the abstractions of allylic hydrogen atoms from alkenes with ${ }^{\bullet} \mathrm{CH}_{3}$ and ${ }^{\bullet} \mathrm{C}_{2} \mathrm{H}_{5}$ radicals strongly favours the formation of 1,3-butadiene, while it has no effect on the conversion of $n$-dodecane.

At lower temperatures, the flow rate analysis displays a completely different behaviour. At $673 \mathrm{~K}$ and a residence time of $250 \mathrm{~min}$ (20\% of conversion as shown in Fig. 5), $n$-dodecane is consumed almost entirely through abstraction of hydrogen atoms by a wide range of alkyl radicals. The six isomers of dodecyl radicals are converted into each other through isomerizations and abstractions of hydrogen atoms from the reactant. The two main pathways consuming the dodecyl radicals are additions to alkenes and $\beta$-scission to produce alkenes and 1-alkyl radicals. The 1-alkyl radicals can in turn isomerize or react by abstraction of hydrogen atoms with $n$-dodecane to produce smaller alkanes. These two pathways consuming the pool of dodecyl radicals have similar net rates. Alkenes react by retro-ene reactions to produce lower alkenes and propene (for example, this pathway accounts for $20 \%$ of the consumption of 1 -octene) and by addition reactions with dodecyl radicals ( $80 \%$ of the consumption of 1-octene) to give alkyl radicals containing more than 12 atoms of carbon. These larger alkyl radicals react by metathesis with $n$-dodecane to produce alkanes heavier than the reactant, which are not produced to any measurable degree in the higher temperature processes. The secondary reactions of these alkane products are very slow.

\section{Conclusion}

This paper presents new experimental results for the thermal decomposition of $n$-dodecane from 950 to $1050 \mathrm{~K}$, a temperature range higher than was investigated before [4-8]. A detailed kinetic model has been proposed and is able, without any a posteriori adjustment of the kinetic parameters, to reproduce the experimental results described here as well as literature data obtained at lower temperatures [4-6].

In order to investigate the potential use of the thermal decomposition of fuel, such as $n$-dodecane to effectively cool the wall of a Scramjet, it will be necessary to couple detailed kinetic models with a CFD code able to reproduce the heat transfer phenomena, such as the NANCY code, which is extensively used at MBDA France to deal with steady heat exchanges [1].

\section{References}

[1] E. Dufour, M. Bouchez, AIAA (2002) 5126.

[2] F. Falempin, M. Bouchez, T. Salmon, P. Lespade, V. Avrashkov, AIAA (2001) 1880.

[3] H. Huang, D.R. Sobel, L.J. Spadaccini, AIAA (2002) 3871.

[4] P. Zhou, O.L. Hollis, B.L. Crynes, Ind. Eng. Chem. Res. 26 (1987) 852.

[5] E.M. Yoon, L. Selvaraj, C. Song, J.B. Stallman, M.M. Coleman, Energy Fuels 10 (1996) 806.

[6] E.M. Yoon, L. Selvaraj, S. Eser, M.M. Coleman, Energy Fuels 10 (1996) 812. 
[7] J. Yu, S. Eser, Ind. Eng. Chem. Res. 26 (1997) 574.

[8] J. Yu, S. Eser, Ind. Eng. Chem. Res. 26 (1997) 585.

[9] V. Warth, N. Stef, P.A. Glaude, F. Battin-Leclerc, G. Scacchi, G.M. Côme, Combust. Flame 114 (1998) 81.

[10] F. Battin-Leclerc, P.A. Glaude, V. Warth, R. Fournet, G. Scacchi, G.M. Côme, Chem. Eng. Sci. 55 (2000) 2883.

[11] V. Warth, F. Battin-Leclerc, R. Fournet, P.A. Glaude, G.M. Côme, G. Scacchi, Comp. Chem. 24 (5) (2000) 541.

[12] R. Fournet, F. Battin-Leclerc, P.A. Glaude, B. Judenherc, V. Warth, G.M. Côme, G. Scacchi, A. Ristori, G. Pengloan, P. Dagaut, M. Cathonnet, Int. J. Chem. Kin. 33 (2001) 574.

[13] R. Bounaceur, V. Warth, P.M. Marquaire, G. Scacchi, F. Dominé, D. Ressort, B. Pradier, O. Brevard, J. Anal. Appl. Pyrolysis 64 (2002) 103.

[14] C. Muller, V. Michel, G. Scacchi, G.M. Côme, J. Chim. Phys. 92 (1995) 1154.

[15] S.W. Benson, Thermochemical Kinetics, second ed., Wiley, New York, 1976.

[16] R.J. Kee, F.M. Rupley, J.A. Miller, Sandia Laboratories Report, SAND 89-8009B, 1993.

[17] P. Barbé, F. Battin-Leclerc, G.M. Côme, J. Chim. Phys. 92 (1995) 1666.

[18] R. Fournet, J.C. Baugé, F. Battin-Leclerc, Int. J. Chem. Kin. 31 (1999) 361.

[19] D.L. Baulch, C.J. Cobos, R. A Cox, P. Franck, G.D. Hayman, Th. Just, J.A. Kerr, T.P. Murrells, M.J. Pilling, J. Troe, R.W. Walker, J. Warnatz, Combust. Flame 98 (1994) 59.

[20] W. Tsang, R.F. Hampson, J. Phys. Chem. Ref. Data, 15 (1986) 1087.

[21] J. Troe, Ber. Buns. Phys. Chem. 78 (1974) 478.

[22] V. Bloch-Michel, Thèse de l'I.N.P.L., Nancy (1995).

[23] C. Chevalier, J. Warnatz, Ber. Buns. Phys. Chem. 94 (1990) 1362.

[24] P.A. Glaude, Thèse de l'I.N.P.L., Nancy (2000).

[25] E. Ranzi, A. Sogaro, P. Gaffuri, G. Pennati, C.K. Westbrook, W.J. Pitz, Comb. Flame 99 (1994) 201.

[26] W. Tsang, J. Phys. Chem. Ref. Data 20 (1991) 221.

[27] R. Fournet, F. Battin-Leclerc, P.A. Glaude, B. Judenherc, V. Warth, G.M. Côme, G. Scacchi, A. Ristori, G. Pengloan, P. Dagaut, M. Cathonnet, Int. J. Chem. Kin. 33 (2001) 574.

[28] H.E. O’Neal, S.W. Benson, J. Phys. Chem. 71 (1967) 2903.

[29] C. Richard, G. Scacchi, M.H. Back, Int. J. Chem. Kin. 10 (1978) 307.

[30] V. Burklé-Vitzthum, R. Michels, G. Scacchi, P.M. Marquaire, Ind. Chem. Ing. Res. 42 (23) (2003) 5791.

[31] K. Bril, P. Goldfinger, M. Letord, H. Mattys, M. Niclause, Bull. Soc. Chim. Belg. 59 (1950) 263.

[32] F. Dominé, D. Dessort, O. Brévart, Org. Geochem. 28 (9-10) (1998) 597. 